by Messrs. Usher, Gray Clegg, Clark Souter, Law, Sorsby and Savin; the spectra of the ash of senile cataract by Mr. Burdon Cooper ; a series of fundus drawings selected by Mr. Rayner Batten ; drawings of pathological conditions by Mr. Leslie Paton and $\mathrm{Mr}$. Juler ; cover test spectacles by Mr. Chavasse ; and red-free ophthalmoscope by Mr. Levy.

\title{
Trade Exhibition
}

Many items of surgical and optical interest were shown in this - exhibition, a catalogue of which was supplied to members.

The exhibition lasted throughout the Congress, and was admirably displayed in one of the lecture rooms of the Royal Society of Medicine. The following is a list of the exhibitors :-Messrs. Bowing, Clifford Brown, Clement Clarke, Curry \& Paxton, Down's, Dixey, Hamblin, Hawes, Keeler, Lewis, Rayner \& Keeler, Uni-Luxe Optical Company, Weiss, and Zeiss.

Saturday, April 14.

Papers were read from 9.30 a.m. to 12 noon. Professor Adolf Gutmann described and demonstrated the piezometer, an auxiliary apparatus for the diagnosis of retrobulbar orbital tumours.

The Congress ended with the Annual General Meeting of the Society and a visit to optical workshops in the west-end, where the various processes in the manufacture of spectacle lenses, safety glass, frames and ophthalmic instruments were admirably demonstrated.

H. B. S.

\section{ABSTRACTS OF PAPERS}

Thursday, April 12.

"The Surgical Treatment of the More Unusual Forms of Squint and Heterophoria, with Especial Reference to End-Results." MR. M. S. MAYOU.

Introduction.-Cases selected from about 700 operations.

Operation used.-Tenotomy with re-attachment of the muscle, or tenotomy with tenectomy. Testing the result at the time of operation with light in the ceiling of the operating theatre. When the operation is finished this should be within $2 \Delta$ or $3 \Delta$ of the final result as tested six weeks after the operation, provided that the muscles have not been unduly pulled upon during the operation. Stitch material used: Japanese fishing gut, boiled.

Hyperphoria.-Low degrees treated by prisms. High degrees 
with diplopia or with torticollis treated by tenotomy of the superior rectus. Cases showing the extreme importance of re-attaching the divided muscle to the eye at the time of operation.

$A$ case of ocular torticollis associated with hyperphoria treated by tenotomy of the superior rectus with advancement of the inferior.

Diplopia occurring in the course of general diseases of the central nervous system simulating concomitant squint (Divergence).

Encephalitis Lethargica.-Whittington gives statistics that such cases occur in 15 per cent. of all chronic forms. Divergent strabismus is usually not worth operating on as the mental condition or the length of time which these patients have to live makes it hardly worth while.

Illustrative case given.

Late syphilitic lesions.-Diplopia occurs associated with what is apparently a concomitant divergence in late syphilitic lesions of the central nervous system. It is similar to that found in encephalitis lethargica, in that it is always divergent, but is not so generally recognized. It is suggested that it is due to a lesion in the convergence centre. Four cases are given between the ages of 35 and 45 years. Two of tabes with an 8 and $10 \Delta$ respectively of divergence, the diplopia caused disappeared entirely after division of the external rectus. Two cases of widely divergent strabismus, one being a case of doubtful G.P.I., and the other with pupillary changes. A tenotomy and advancement was performed in each case, the diplopia was completely cured and they were well and at their ordinary work two and a half years after the operation.

Congenital defect of the external recti associated with convergence.-These cases may be unilateral or bilateral, the bilateral being undoubtedly congenital and probably the unilateral in most cases, although birth injury in some cases has been suspected; they may be associated with other congenital deformities. They are in two groups, one associated with enophthalmos in which the internal muscles and check ligaments seem to be bound down on the inner side of the orbit and the other where there is no enophthalmos. All the cases operated on showed no enophthalmos. Emphasis was laid upon the importance of operating in early life, otherwise diplopia resulted from the operation. Three cases of congenital defect of the external recti were operated on by a tenotomy and advancement and in two of the cases although the eyes were straight after the operation, there was no outward movement. In the third case the muscle held in the Prince's forceps was felt to contract and there was some slight return of the outward movement in the eye subsequent to the operation. One unilateral case with extreme convergence was operated on. The return of movement in this case was extremely good. 


\section{Discussion}

Opener :-DR. F. Bernard Chavasse's paper included the following headings :-

The similarity between cases of congenital abducens palsy and cases of "essential" alternating convergence " due to total absence of the fusion faculty." Lessons learned from the operative treatment by simple methods of these cases. The superimposition of ordinary concomitant convergence in cases in which the abducens palsy is very slight. The early rotation of the head away from the paretic abducens in young children and the simulation in them of conjugate deviation. The relation of these alternating cases to cases of ocular torticollis, first those cases in which there is as yet no superimposed convergence and secondly those in which, with the development of convergence, the torticollis has disappeared. The so-called spasm of the inferior oblique in these cases and the less well recognized spasm of the internus. Operated and other cases. From a consideration of the operative treatment of spasm to that of contracture. Operative treatment of contracture at different ages. The operative treatment of amblyopic or blinded convergent or divergent eyes. Some other odd and instructivecases.

Mr. W. H. MCMullen.

Ocular torticollis.-The commonest form of ocular torticollis is that in which the head is tilted towards one shoulder, resembling torticollis due to shortening of a sterno-mastoid. When the head is in this position there is no strabismus; but when it is straightened and still more when it is tilted in the opposite direction, the eye on the side opposite to that to which the head is habitually inclined deviates upwards.

Consideration of the exact nature of the defect is essential before one can discuss treatment. By most writers this form of ocular torticollis is attributed to congenital paralysis of the superior oblique muscle on the side opposite to that towards which the head is tilted. Although there are some difficulties in accepting this hypothesis it appears to be the most reasonable explanation of the majority of cases. The torsional effect of the muscle is probably the most important factor. When the head is inclined to the right the eyes normally roll in the opposite direction, the left into a position of extorsion. Relaxation of the superior oblique being necessary in this rotation, the eye can assume its correct position when that muscle is paralysed. When the head is straightened a movement of intorsion is required to bring the left eye into normal position. This movement is effected mainly by contraction of the superior oblique and superior rectus. If the former is paralysed the superior rectus, acting alone, causes upward rotation with little intorsion. 
It has been suggested that the condition may be due to some congenital defect in the mechanism concerned in the postural eye reflexes excited by impulses originating in the labyrinth or the neck muscles. The deviation occurs if the head is straightened when the patient is lying flat on the back, looking at a light overhead. Labyrinthine reflexes, therefore, cannot be concerned.

The majority of the cases seen by the writer appeared to be due to a superior oblique palsy. Recently he had a case in which there was paresis of the superior rectus of one eye and probably also of the superior oblique of the other eye.

Ocular torticollis has been treated surgically in only a small proportion of cases, yet it is much less common in adults than in children. It seems, therefore, that there must be a tendency to spontaneous recovery, comparable to that seen in some other forms of congenital ocular palsy, e.g., ptosis. In some cases the torticollis may disappear because the patient learns to tolerate diplopia rather than always keep the head tilted.

Treatment.-In view of the tendency to spontaneous improvement it is not advisable to operate upon children showing slight degrees of the defect. The wearing of prisms has been effective in a few cases, but generally proves useless. It is possible that exercises under skilled control might be beneficial, but no record of cases so treated is known to the writer.

If the deformity be considerable, and if no improvement be apparent after several months treatment with prisms and exercises, the question of operation has to be considered. In cases attributable to paresis of a superior oblique, three methods of surgical treatment appear to deserve consideration :-

1.-Tenotomy, or, more correctly, myotomy of the inferior oblique on the same side. Few surgeons have attempted this operation. Doyne, in 1926, reported two cases. A good result was. obtained in one, in the other only doubtful benefit. Temple Smith in a recently published paper claims to have obtained very satisfactory results in several cases. Those who have performed this operation state that it is less difficult than one would expect. The great objection to it would appear to be the impossibility of controlling the result. The muscle is divided close to its origin, and there must be grave risk of the cut end slipping far back into the orbit.

2.-Displacement of the insertion of the superior rectus on the same side. The object of this operation, described by Jackson, is to increase the power of intorsion of the muscle while lessening its power of superduction. The tendon is detached from the globe and reattached in a position external and slightly posterior to its original insertion. The writer performed this operation in one case. The effect appeared to him very slight, but the child's mother thought he kept his head much straighter. 
3.-Tenotomy or recession of the inferior rectus on the opposite side. The plane of action of the inferior rectus lies at an angle of about $28^{\circ}$ to the plane of the superior oblique of the opposite side, so that the two muscles have a nearly parallel action. Very good control of effect is possible with this operation. Where a very considerable effect is required it may be combined with advancement of the superior rectus. The majority of writers recommend this as the operation of choice. The writer agrees that it appears to offer the best prospect of a satisfactory result. $\mathrm{He}$ has, however, tried it only once, and that too recently to allow of statement of end result.

Strabismus due to congenital paralysis of the external rectus.In this condition advancement of the tendon of the paralysed muscle and Tenon's capsule with recession of the internal rectus may give an unexpectedly good result. An eye totally lacking power of abduction may after operation gain an appreciable range of abduction, which may be explained by the fact that when the eye is straight the two oblique muscles have considerable power of abduction, especially when the action of the internal rectus has been weakened.

\section{"Pulmonary Embolism following Ophthalmic Operations."} Mr. E. WolfF.

(1) Many more cases than the literature would leave one to suppose.

(2) Theories with regard to the causation of Pulmonary Embolism generally.

(3) The operation on the eye per se has probably nothing to do with it.

(4) A case is described which may help to throw some light on the causation.

(5) Some tentative suggestions.

"Obstruction of the Central Artery of the Retina with Simultaneous Hemiplegia." Mr. M. Whiting.

Description of a case showing these features with a discussion of the possible pathology.

"Retinal Abiotrophy." Mr. A. Sorsby.

Paget's conception of " premature degenerations ... diseases only in consideration of the time of their occurrence" (1853).

Gowers' "Abiotrophy" (1902).

The modern application of terms dystrophy and abiotrophy. Hereditary ocular degenerations-" Ophthalmic abiotrophies" - Treacher Collins (1919-20).

Leber's concept of tapeto-retinal degeneration (1916)-comparison with Treacher Collins.

An attempted classification of retinal dystrophies. 


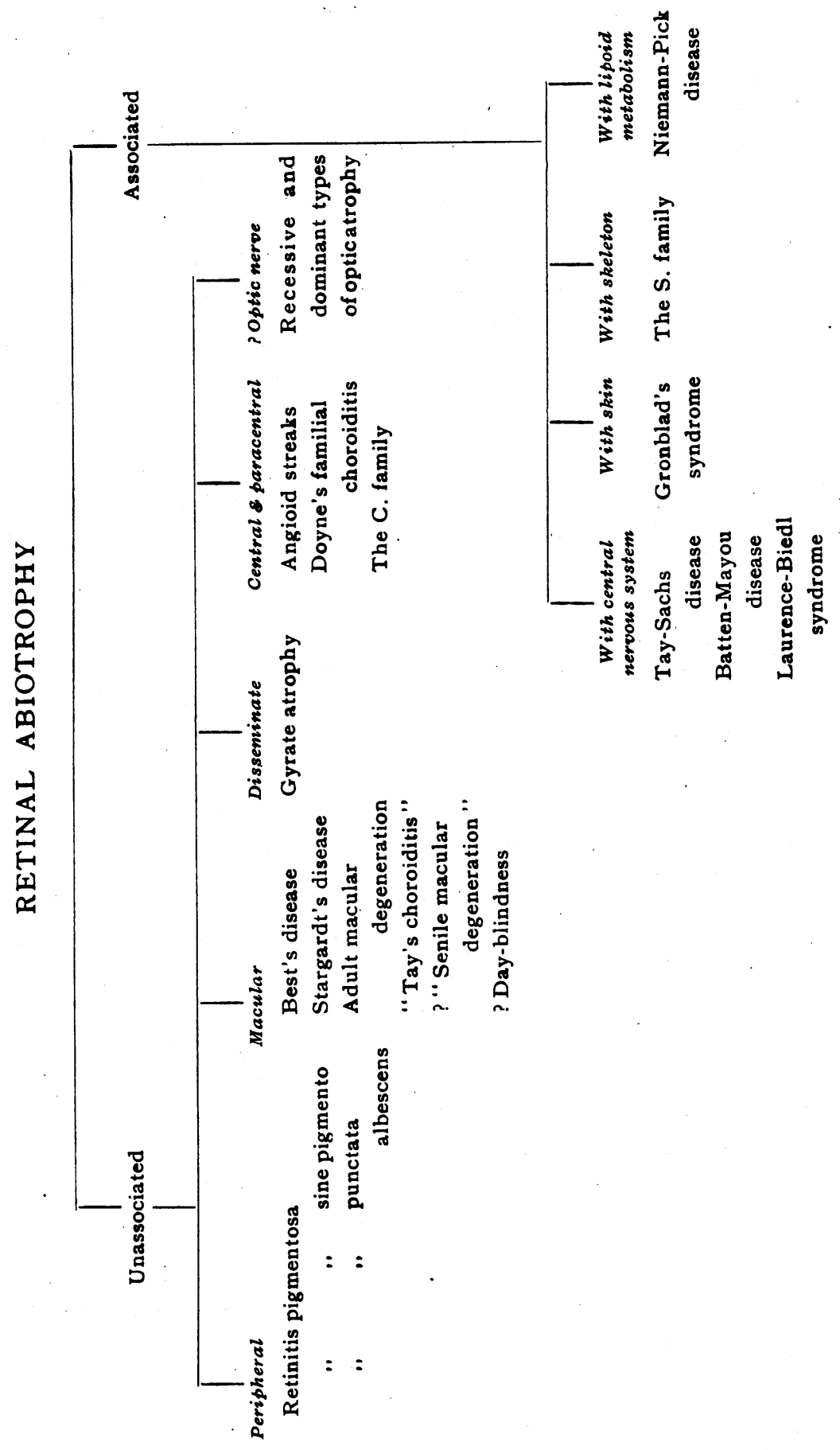


“Atropine Irritation and its Prevention." Mr. R. G. WALler. Atropine irritation from the clinical point of view is discussed. Sensitivity to atropine presents certain aspects not unlike the phenomena known as "allergic." So far as is known there can be no true allergy in connection with a pure alkaloidal salt such as atropine sulphate since allergic phenomena are associated with proteins.

The possibility of a chemical or physical combination between atropine sulphate and the proteins of tears is suggested and a rational line of therapy is based on this assumption.

A technique is described for the preparation of a solution of the alkaloid in human tears with a view to obtaining an alkaloid-protein combination to be used as a desensitising agent.

An account is given of the therapeutic effects obtained in a series of 30 cases which have been investigated since January, 1933.

\section{"Calcium and Parathyroid Therapy in Progressive Myopia." Mr. F. W. LaW.}

Twenty-nine cases of proved progressive myopia occurred in some 800 cases in the routine refraction of school children. All were ordered calcium and parathyroid by mouth for a year; an endeavour is made to estimate the value of this form of treatment in arresting the progress of the myopia.

\section{FrIDAY, APRIL 13.}

\section{"Retinal Detachment in Aphakia." Mr. C. DeE Shapland.}

An investigation into all cases of retinal detachment occurring in aphakic subjects admitted to the wards of the Royal London Ophthalmic Hospital during the four years 1930-1933 inclusive. The cases are divided into two groups-those in which the detachment followed needling of soft cataract and those in which it followed extraction of hard cataract. The incidence of these conditions has been worked out, factors in the aetiology noted and the operative results surveyed. Lastly, points in prophylaxis are suggested.

\footnotetext{
"Further Technique in the Operative Treatment of Detached Retina." Mr. Cole Marshall.

Charts used in marking out the tears.

The preparation of the patient before the operation. Cibelgin, Nautisan, Pantocaine.

Points in connection with the operation. The varieties of needle points used. The question of diagnostic puncture. Surface coagulation combined with micro-puncture. The treatment of different
} 
types of tears :- shallow and bulbous detachments; disinsertions, so-called.

The evacuation of the sub-retinal fluid.

\section{“Agranulocytic Anaemia with Retino-choroidal Lesions." SIR ARNOLd LAWSON.}

The patient was a man, aged 73 years, in well-to-do circumstances who first came under suspicion of a general toxaemia in December, 1932, from the fact that he was suffering from severe and chronic retinochoroidal changes of considerable standing for which there was no obvious local cause.

The most probable cause was sinusitis, of which there was a very long history going back as far as 1910, when Mr. Herbert Tilley treated him for antral infection. During the next 20 years he suffered off and on from attacks of sinusitis and was seen occasionally by Mr. Mollison. In the early part of 1932 he was much troubled with symptoms of frontal sinus infection for which he saw Mr. Mollison, who finally opened and drained the right frontal sinus in August, 1932. In the early part of 1933 he had an attack of acute tonsillitis. At this time a blood count was made, and the examination showed a very severe leucopenia with very marked diminution of the polymorphonuclear cells.

In May, 1933, he had another acute attack of the same complaint followed by thrombosis in the right leg. An autogenous vaccine was tried in the autumn of 1933 when he was better, but this did little for him, and as he had a further recurrence of tonsillitis and pyrexia during the use of the vaccine it was discontinued. From this time he went rapidly downhill, and died November 20, 1933.

A differential blood count taken two days before death, and confirmed by another count taken the next day, showed that the leucopenia had not increased but that the polymorphonuclear cells were completely absent (agranulocytosis).

The eyes were examined from time to time during the last 18 months of his life, and during this period the retino-choroidal disease slowly increased with progressive failure of vision.

Dr. Bellingham Smith who made the diagnosis has kindly consented to make some remarks upon agranulocytosis, pointing out what is known of the aetiology, pathology and treatment of this rare blood condition.

\section{“Cerebro-spinal Rhinorrhoea following Fracture." SIR ARNOLD Lawson.}

The patient, a youth of 21 years, when bicycling on a dark winter night,, without lamps, had a head-on collision with another bicyclist 
also without lamps. Both fractured their skulls and were found unconscious at the side of the road some time later.

The patient who is the subject of this report was seen very shortly afterwards by Mr. Elkington, of Newport, Salop, who found him still unconscious and bleeding violently from the nose with symptoms of severe haemorrhage into both orbits which caused considerable proptosis of both globes, particularly the left. There was also chemosis of the conjunctiva. The progress of the patient was good and rapid, but after about three weeks there was marked recession of the left globe and the patient complained of diplopia on extreme lateral movements of the eyes.

The patient was sent to me for examination about eight weeks after the accident. I then noted that the patient was using his handkerchief a great deal, and questioning elicited that he had suffered from what he called a cold for about two or three weeks characterized by almost continual dropping of clear fluid from the left nostril. I suspected the fluid to be cerebro-spinal in origin, and had an analysis made which proved this to be the case. Further X-ray examination showed that one limb of the fracture involved the left frontal sinus, and another limb the left orbit. The patient was subsequently admitted to University College Hospital where an operation was undertaken by Mr. Wilfred Trotter and Mr. Julian Taylor to close the dural opening if possible, or failing the possibility of doing this to close the opening into the left frontal sinus. The former was found impossible and the frontal sinus opening was closed with a connective tissue graft. The patient, however, succumbed from meningitis.

Mr. Julian Taylor has very kindly consented to speak with regard to the present-day surgical position of cerebro-spinal rhinorrhoea and the chances of saving the patient by operation, without which a fatal issue is of necessity unavoidable in course of time.

\section{"Third Nerve Paralysis due to Leaking Aneurysm Confirmed by Arterial Radiography." PROFESSOR EDWIN BRAMWELL.}

A case record-ligature of internal carotid artery-immediate disappearance of pain and gradual improvement of paralysis.

Remarks on aneurysms of cerebral arteries. A case of leaking aneurysm of Circle of Willis. Third nerve paralysis which was improving when fatal rupture occurred. Post-mortem appearances.

Another case of third nerve paralysis in which an aneurysm was demonstrated by arterial radiography-ligature of internal carotid.

Brief remarks on arterio-radiography of cerebral arteries.

Possibilities of treatment.

Some observations upon the aetiology of recurrent and periodic ocular palsy. 
"Some Varieties of Optic and Retrobulbar Neuritis." DR. W. RuSSELl BRAIN.

1. Signs and symptoms considered in relation with the anatomical situation of the lesion.

(i) Papillo-macular form.

(ii) Optic neuritis.

(iii) Retrobulbar neuritis.

(iv) Chiasmal neuritis.

(v) Mixed forms.

2. Clinical varieties.

(i) Acute papillo-macular neuritis.

(ii) Acute unilateral optic and retrobulbar neuritis.

(iii) Acute bilateral optic and retrobulbar and chiasmal neuritis.

(1) "Idiopathic" forms.

(2) Following severe haemorrhage.

(3) In pregnancy and the puerperium.

(4) Associated with myelitis.

(5) Associated with polyneuritis.

3. Observations on the differences between unilateral and bilateral forms.

"The Representations of the Areas of the Retina in the Lateral Geniculate Body." Mr. G. Penman.

The lateral geniculate body is arranged in laminae of cells, in which the optic nerve fibres terminate, those from the same and from the opposite side going to different laminae.

The macular area is more restricted than previous observations have suggested, and is represented by a median sector which is definitely limited to the caudal two-thirds of the nucleus. It involves all the cell laminae.

Fibres from the nasal half of the macula undergo complete decussation in the chiasma, while those from the temporal half remain uncrossed. The whole width of the cell laminae in the oral third of the nucleus is concerned with peripheral vision.

The upper part of the retina is represented in the medial portion of the nucleus, the lower in the lateral portion, as stated by Brouwer and Zeeman.

The evidence is derived partly from animal experiments and partly from observations on pathological conditions in human beings.

\section{"The Percentage Incidence of the Different Types of Senile}

Cataract." Mr. JOHN Foster and Mr. JOHN Benson.

(1) Although the use of the slit-lamp and corneal microscope has given us a clearer picture of the different forms of senile cataract 
in recent years, there are no figures in the English literature regarding the relative incidence of these forms.

(2) Continental literature on these lines is given below.

JEss, A.-Die Linse und ihre Erkrankungen; Die krankhaften Altersveränderungen der Linse. In: Schieck \& Brückner, Kurzes Handbuch der Ophthalmologie, Vol. V, p. 212, 1930.

BARTH, T.-Untersuchungen über Häufigkeit und Lokalisation von beginnenden Linsentrübungen bei 302 über 60 Jahre alten Personen. Zeitschr. $f$. Augenheilk., Vol. XXXII, pp. 8, 143, 1914.

Handmann, M.-Ueber den Beginn des Alterstares in der unteren Linsenhälfte ; klinisch-statistische Bemerkungen über die Cataracta glaukomatosa und diabetica. Klin. Monatsbl.f. Augenheilk., Vol. XLVII, pp. 692-720, 1909.

Horlacher, J.-Das Verhalten der menschlichen Linse in Bezug auf die Form von Alterstrübungen bei 166 Personen im Alter von 41-83 Jahren. Zeitschr. f. Augenheilk., Vol. XL, pp. 33-49, 1918.

Bueklers.-Klin. Monatsbl. f. Augenheilk., Vol. LXXXVII, p. 527, October, 1931.

(3) The authors' approach to this subject has been from a slightly different point of view, namely surgical significance rather than the numerical incidence of these types in all cases of senile cataract. They have analysed with the slit-lamp and ophthalmoscope such cases of senile cataract attending the Leeds General Infirmary as have had a reduction of vision to "6/18 or under" in one or both eyes, those cases in which other disease was present and might have affected the vision having been rejected for the first part of this paper. In this way it was hoped to discover the relative incidence of those types of cataract which have the greatest effect on visual acuity and are, therefore, most important from the surgical point of view.

(4) The second half of the paper was to have been devoted to the surgical significance of these different types from the point of view of their effect on the course of the operation and its outcome. It is doubtful, however, if enough results will have been collected on these lines to complete the second half of the paper by the time of the meeting.

\section{"Iris Changes Revealed by Simple Diascleral Diaphanoscopy." Dr. Clark Souter.}

Attention is directed to the occurrence in a wide variety of case of changes in the iris which may not be visible by ordinary loupe or lens inspection, but which are revealed by simple diascleral, and most often diapalpebral, diaphanoscopy.

Explanations are offered as to the possible origin and mechanism of some of these changes, as well as of some fallacies in the examination, whilst further investigation by this easily carried out method is recommended as likely to yield very interesting and often important results in many obscure cases of accident and disease affecting not only the anterior, but the deeper parts of the eye. 
"TheVascular Control of the Intra-ocular Pressure." Mr. Rycroft.

Experiments showing influence of arterial and venous pressure on the intra-ocular pressure of the cat.

The rôle of the choroidal capillary meshwork. The local intrinsic control of the intra-ocular capillaries by axon reflex and the regulation thereof.

Influence of retrobulbar injections on the intra-ocular pressure. Clinical deductions.

"Clinical and Post-mortem Notes on a Case of Budd's or Chiari's Disease preceded by Exudative Retinitis, Iridocyclitis and Secondary Glaucoma." MR. L. SAvin.

In 1845 Budd described a case of idopathic thrombosis of the hepatic veins. In 1899 Chiari summarized the literature and described three cases. In spite of Chiari's recognition of the work of Budd and others, the condition is commonly called Chiari's disease. Syphilis is not the usual cause of the thrombosis. Sudden and complete obstruction to the hepatic veins causes delirium, coma, and death in about two days. A more chronic type may last months, and is characterised by epigastric pain, ascites, an enlarged tender liver of nutmeg type, a collateral circulation as in cirrhosis, clubbed fingers and toes, and cyanosis. Death follows vomiting and coma.

The case described in this paper was of the chronic type and postmortem showed hepatic vein thrombosis extending to the inferior vena cava, which was completely filled by ante-mortem clot. The liver was of nutmeg type. The case is remarkable as also showing exudative retinitis, peculiar retinal vascular changes, bilateral iridocyclitis, and in one eye a cupped and atrophic disc from secondary glaucoma. An eye was not obtained for microscopic section.

Recent work on intravascular thrombosis is summarized.

\section{Saturday, April 14.}

“The Treatment of Relapsing Corneal Ulceration by Modified Peridectomy." DR. M. S. Wellwood Ferguson.

Short summary of methods used to combat this type of ulceration. Types of case responding to treatment-mainly those due to endogenous infection. Probable pathology'underlying the frequent relapses.

Description of operation adopted. Anaesthesia required, and after treatment.

Notes on typical cases, and summary of results of 50 consecutive cases. 
"Nodular Keratitis : the Pathological Sequel to a Case Reported Thirty Years Ago." DR. Leslie Buchanan and DR. Chesar MichaELSON.

A pathological report of both eyes removed post-mortem is given together with photographs illustrating the histological changes. Based on those findings and on an investigation into the literature of the disease an interpretation of the underlying pathological processes is suggested. The authors are of the opinion that the primary lesion is a very chronic keratitis underneath the membrane of Bowman.

\section{"Ulcerative Tuberculoma of the Conjunctiva with a Report of a Case." Mr. H. NeAme.}

A woman, aged 63 years, gave only nine days' history of redness with a swelling on the white of one eye, and some discharge. No family history of tuberculosis and no injury. The right eye presented a firm red swelling on the nasal part of the sclerotic, with a deep ulcer with undermined edge. Wassermann reaction negative.

As the vision was reduced to finger counting at two feet, and atrophic patches of old choroiditis were visible at the macula through cortical lens opacities, the eye was enucleated.

Histological examination showed a caseating granulomatous mass containing giant-cells, over-lying the sclera from the corneal margin back to the equator. Tubercle bacilli were not found. Other cases from the literature are discussed.

\section{“Experimental Grafts of Devitalised Corneal Tissue." Mr. \\ TUdor THOMAs.}

The paper gives an account of the progress of two experimental corneal grafts in rabbits, transplanted with the object of ascertaining the reaction of the eye to grafts of corneal tissue devitalized by heat. The grafts were taken from other rabbits, and after removal were placed in olive oil at a temperature of $100^{\circ}$ Centigrade for 15 seconds and 45 seconds respectively.

Each became united, and the reaction of the eye in each case was minimal.

\section{"Heterophoria in Aviation: Its Significance and its Treatment." SQUADRON-LEAdER P. G. LIVINGSTON.}

The importance of visual judgment in modern flying cannot be over-stressed. The manoeuvring speed of aircraft is increasing year by year, and though the landing speed is kept within certain limits by various mechanical devices, it is, with the passage of time becoming definitely greater.

Thus many factors arise which stand apart from the normal ocular estimations of everyday life. It has been proved beyond 
doubt that heterophoria is an outstanding cause of errors of judgment in landing. The condition may develop in the borderline cases admitted while they are undergoing flying training, or it may come about as a complication of head injuries with concussion, with a marked convergence weakness as is commonly shown. It may result from the effects of illness at home, e.g., influenza, or those endemic to some tropical country, e.g., sandfly fever, or through continued exposure to sun glare.

The training of cases so suffering by amblyoscopic and stereoscopic exercises has shown that, with care in selection, over 90 per cent. of cures have been brought about ; and pilots who of necessity had to be taken off flying duty, have returned to their full category and continued in the Service without mishap.

The application of ocular muscle training to cases of heterophoria calling for operation is an important one, and the benefits likely to result from such training as a pre-operative and post-operative measure is stressed.

The technique of ocular muscle training for heterophoria as applied to the cases which arise in the Service is discussed.

"The Piezometer, an Auxilliary Apparatus for the Diagnosis of Retrobulbar Orbital Tumours." PROFEsSOR AdOLF GUTMANN.

- This paper is a brief description of a new apparatus for measuring the displacement backwards of the eye into the orbit under a known pressure. It is claimed that exophthalmos gives different readings on the instrument according to whether the proptosis is due to oedema, angioma or malignant tumour.

\section{ABSTRACTS}

\section{I.-UVEAL TRACT}

(1) Villard, $\mathrm{H}$. and Dejean, Ch. (Montpelier).-Cysts of the iris. (Les Kystes de l'Iris). Arch. d'Ophtal., February, March, April, 1933.

(1) The increase in our knowledge concerning cysts of the iris resulting from recent biomicroscopical and histological examination, has demonstrated that the subject hitherto "fairly simple" is really one of considerable complexity. A case which came under their observation led Villard and Dejean to the conclusion that the subject merited re-examination and an attempt to clear up some of the indeterminate ideas concerning the origin and pathogenis of these tumours. They have carried out their investigation 